\title{
PERFORMANCE EVALUATION OF CI ENGINE FUELLED WITH WATER EMULSIFIED DIESEL OIL
}

\author{
Sangeeta Das ${ }^{1}$ \\ ${ }^{1}$ PhD Scholar, Department of Mechanical Engineering, NERIST, Arunachal Pradesh, India-791109
}

\begin{abstract}
It is well known that diesel engines are the most efficient internal combustion (IC) engines used in transportation sector due to its higher thermal efficiency, simple and rigid structure. However, they produce hazardous emissions such as oxides of nitrogen $\left(N O_{X}\right)$, particulate matter, smoke and obnoxious odour in high amount. In this work, attention is focused to retain the performance and to reduce the emissions from diesel engines by using one of the fuel modification techniques, water-diesel emulsion, in a stationary diesel engine without any engine modification. Stable diesel emulsion samples with 5\%, 10\%, 15\% and 20\% water content are prepared with the help of proper mixing technique and emulsifying agent which are then used in a fully instrumented single cylinder, four stoke, water cooled, VCR, DI 'Kirloskar' make diesel engine at varying loads and constant speed. Various fuel characteristics like density, viscosity, calorific value, flash point, cloud and pour point, etc., are evaluated for the samples. It has been found that the performance of the engine is slightly improved in terms of brake thermal efficiency when $20 \%$ waterdiesel emulsion is used because of its minimum brake specific energy consumption and predominant effect of micro-explosion phenomena during combustion. The average increase in brake thermal efficiency (BTE) is approximately $2.5 \%$ compared to pure diesel over the entire load range for this engine. Also the exhaust gas temperature and $\mathrm{NO}_{X}$ emission for $20 \%$ blend is lower than diesel fuel by $8.6 \%$ and 30\%, respectively. However, carbon monoxide (CO) and unburnt hydrocarbon (UBHC) emissions with $20 \%$ water-diesel emulsion are marginally higher than those with pure diesel. Thus, considering the engine performance, emission characteristics and local environmental conditions, $20 \%$ water-diesel emulsion is the most suitable water-diesel emulsion blend.
\end{abstract}

Keywords: Water-Diesel Emulsion, Micro-Explosion, Water-In-Oil, Oil-In-Water, Emissions, BTE, NO, CO, UBHC

\section{INTRODUCTION}

Diesel engines are the most efficient internal combustion (IC) engines which are extensively used in transportation, agricultural, energy production and industrial activities owing to its high thermal efficiency, simple and rigid structure. Because of its ever increasing demand, there is rise in demand and usage of fossil fuels. As a result, fossil fuels reserves are depleting day by day. Besides its wellknown advantages, diesel engines are also responsible for creating pollution to a large extent. The major pollutants of diesel engines are oxides of nitrogen $\left(\mathrm{NO}_{\mathrm{X}}\right)$, particulate matter (PM), black smoke, carbon monoxide (CO), hydrocarbon (HC), obnoxious odour, etc., which are detrimental to the environment, especially to human health. Therefore, to keep intact the performance of diesel engines while keeping in mind the environmental concerns and fossil fuel depletion matters, many researchers have tried various techniques such as fuel modification, engine design alteration, exhaust gas treatment, etc.

The mechanisms of formation of $\mathrm{NO}_{\mathrm{X}}$ and particulate matter (PM) in the combustion chamber of diesel engines are contradictory. The simultaneous reduction of both is very difficult and cannot be achieved by one particular technique. The assemblage of many techniques along with after treatment may be an option to reduce these emissions but it may be an expensive solution with system complexity owing to the added cost including initial investment, maintenance, and extra energy consumption by the devices, etc [1]. Therefore, water-in-diesel (W/D) emulsion, a simple technique, has been developed to reduce $\mathrm{NO}_{\mathrm{X}}$ and smoke emission simultaneously which can be used without engine modification. Water-in-diesel emulsion fuel contains water and diesel which are mixed uniformly on volume basis with the help of appropriate surfactants to produce stable emulsion. There are two forms of emulsion: one is water-inoil (W/O) emulsion in which the water is the dispersed phase, whereas in oil-in-water $(\mathrm{O} / \mathrm{W})$ emulsion oil is the dispersed phase.

The usage of water-in-diesel emulsion has several benefits. With the use of W/D emulsion there is an improvement in the mixing process caused by two phenomena: the first provides an additional momentum in jet behaviour and the second, more important phenomenon, is the micro-explosion of inlet water droplet which produces a secondary atomization thus improving the mixing process [2]. When emulsified fuel droplets are sprayed into the combustion chamber, they are further atomized as a result of the violent transformation of their water content into steam. This conversion of water into steam shatters the oil surrounding that water into much smaller droplets and this phenomena is known as micro-explosion. There are many physical and chemical effects of water addition which are clearly explained by F.L. Dryer [3] in his literature. Kadota and Yamasaki [4] have given a detailed description about microexplosion phenomenon. Another confirmed benefit of W/D 
emulsion is that the vaporization of water absorbs the heat of the emulsion causing a decrease of local adiabatic flame temperature and therefore restrains the generation of $\mathrm{NO}_{\mathrm{X}}$ and its emission in the exhaust [2]. Lif and Holmberg [5] have reported that $15 \% \mathrm{~W} / \mathrm{D}$ emulsion can give a reduction in $\mathrm{NO}_{\mathrm{X}}$ up to $35 \%$ under regular conditions. Use of W/D emulsion lengthens the ignition delay period which is confirmed through various experimentations $[6,2,4]$. There is also an improvement in brake thermal efficiency with the use of emulsified fuel which is highlighted in many literatures. Abu Zaid [7] has reported that the average increase in brake thermal efficiency for $20 \%$ water-diesel emulsion is approximately $3.5 \%$ over the use of diesel for the engine speed range studied. $\mathrm{CO}$ and $\mathrm{HC}$ emission levels are always higher than base diesel due to incomplete combustion on account of low temperature [1]. Samec et al. [8] have studied numerically and experimentally some of the physical and chemical properties of W/D emulsion on combustion characteristics.

The objective of the present work is to evaluate experimentally the engine performance parameters and emission characteristics of a CI engine using water emulsified diesel oil as fuel and to establish a suitable water/diesel ratio in the fuel.

\section{SYSTEM DESCRIPTION}

\subsection{Experimental Set-Up}

The experiments were conducted on a single cylinder, four stroke, VCR, water cooled DI diesel engine connected to eddy current type dynamometer for loading. The schematic diagram of the experimental set-up is shown in Fig. 1 and the general specifications of the engine are given in Table 1. The engine is equipped with crank angle sensor, piezo-type cylinder pressure sensor, thermocouples to measure the temperature of water, air and gas, rotameters to measure the water flow rate and manometers to measure the fuel flow and air flow. The setup enables study of the engine on line performance for brake power, indicated power, frictional power, brake and indicated mean effective pressure, brake and indicated thermal efficiencies, mechanical efficiency, volumetric efficiency, specific fuel consumption, air-fuel ratio and heat balance through a Lab View based Engine Performance Analysis software package "Engine soft LV". The various gas emissions like $\mathrm{HC}, \mathrm{CO}, \mathrm{CO}_{2}, \mathrm{O}_{2}$ and $\mathrm{NO}_{\mathrm{X}}$ are measured using AVL DIGAS 444 analyzer.

\subsection{Sample Preparation}

The water emulsified diesel fuel are prepared by mixing $5 \%$, $10 \%, 15 \%$ and $20 \%$ water with diesel on volumetric basis. Two surfactants Span80 and Tween80 are used to prepare the emulsion whose combined concentrations are varied from $0.5 \%$ to $2.0 \%$. This is because at low surfactant concentrations, the emulsions will separate which will extinguish the flame when separated water portion enters the combustion chamber. Moreover, too large quantity will cause creaming of the emulsion, that can hardly burn, or would clog the pump blades and thus impairing their movements and actions [9]. The mixer of water, diesel and surfactant is stirred for about 4-5 minutes with the help of a mechanical agitator and the emulsification of these three different liquids produces a white, creamy solution. The minimum surfactant concentrations required to stabilize various emulsified fuel samples is shown in Table 2 and 5\% W/D emulsion prepared with $0.5 \%$ surfactant concentration is shown in Fig. 2.

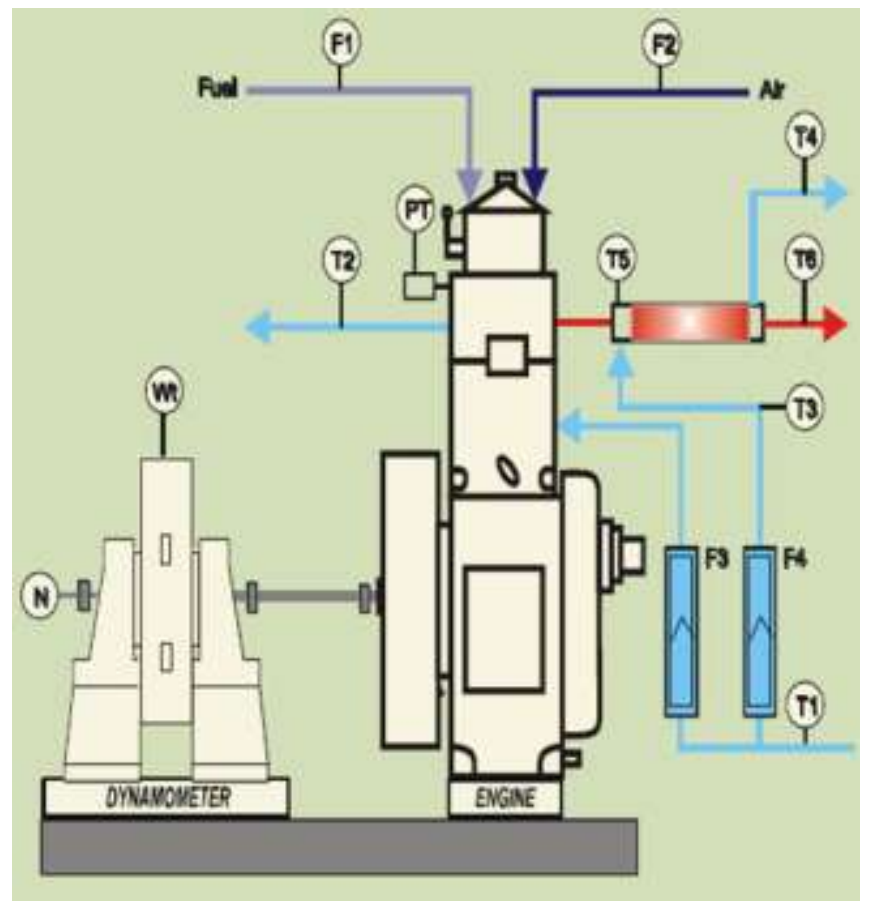

F1 - Fuel injector pressure

F2 - Air consumption measurement

F3 - Water flow through engine

F4 - Water flow through calorimeter

T1 - Engine water inlet temperature

T2 - Engine water outlet temperature

T3 - Calorimeter water inlet temperature

T4 - Calorimeter water outlet temperature

T5 - Exhaust gas to calorimeter inlet temperature T6 - Exhaust gas from calorimeter outlet temperature

PT - Piezo sensor N rpm pick up and TDC encoder

Fig -1: Schematic diagram of experimental set-up

Table -1: Specification of the diesel engine

\begin{tabular}{|l|l|}
\hline Make & Kirloskar \\
\hline Rated Brake Power $(\mathrm{bhp} / \mathrm{kW})$ & $7 / 5.2$ \\
\hline Rated Speed $(\mathrm{rpm})$ & 1500 \\
\hline Bore $\times$ Stoke $(\mathrm{mm} \times \mathrm{mm})$ & $110 \times 87.5$ \\
\hline Compression Ratio & 17.5 \\
\hline Inlet Valve Open (Degree) & 4.5 degree before TDC \\
\hline Inlet Valve Closed (Degree) & 35.5 degree after BDC \\
\hline $\begin{array}{l}\text { Exhaust Valve Open } \\
\text { (Degree) }\end{array}$ & 35.5 degree before BDC \\
\hline $\begin{array}{l}\text { Exhaust Valve Closed } \\
\text { (Degree) }\end{array}$ & 4.5 degree after TDC \\
\hline $\begin{array}{l}\text { Fuel Injection Timing } \\
\text { (Degree) }\end{array}$ & 23 degree before TDC \\
\hline
\end{tabular}


Table -2: Surfactant concentration required to stabilize water emulsified fuel samples

\begin{tabular}{|l|l|}
\hline $\begin{array}{l}\% \text { of water in the } \\
\text { emulsion }\end{array}$ & $\begin{array}{l}\text { Minimum surfactant } \\
\text { concentration (\%) }\end{array}$ \\
\hline 5 & 0.5 \\
\hline 10 & 1.0 \\
\hline 15 & 1.5 \\
\hline 20 & 2.0 \\
\hline
\end{tabular}

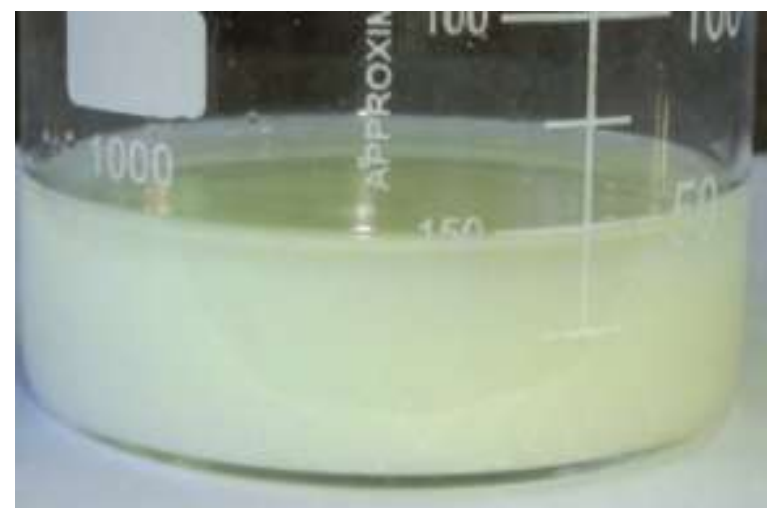

Fig -2: $5 \%$ W/D emulsion with $0.5 \%$ surfactant concentration showing milky emulsion with no deposition

\subsection{Stability Study}

Once the proper water-diesel emulsions are prepared, the stability of the solutions is checked by keeping the solutions in rest for several hours in measuring cylinders. In this study, the emulsion stabilities of the two phase water-diesel samples are determined visually based on the percentage of separation of emulsion, which is represented by the extent of the separation phenomenon of the emulsion and the stability time.

\subsection{Fuel Characterization}

Five fuels were tested: commercial diesel oil and the same diesel after emulsification with 5\%,10\%, $15 \%$ and $20 \%$ water. Their main characteristics are shown in Table 3.

Table -3: Physico-chemical Properties of Test Fuels

\begin{tabular}{|l|l|l|l|l|l|}
\hline \multirow{2}{*}{ Propert-ies } & \multicolumn{5}{l|}{ CI Engine Fuel } \\
\cline { 2 - 7 } & Diesel & $5 \%$ W/D emulsion & $10 \%$ W/D emulsion & $15 \%$ W/D emulsion & $20 \%$ W/D emulsion \\
\hline Calorif-ic value $(\mathrm{kJ} / \mathrm{kg})$ & 42000 & 39690 & 37380 & 35071 & 32761 \\
\hline Density at $20^{\circ} \mathrm{C}\left(\mathrm{kg} / \mathrm{m}^{3}\right)$ & 840 & 848.3 & 853.5 & 863.3 & 872.6 \\
\hline Kinematic viscosity at $20^{\circ} \mathrm{C}(\mathrm{cSt})$ & 2.869 & 3.375 & 4.763 & 8.569 & 10.228 \\
\hline Cloud point $\left({ }^{\circ} \mathrm{C}\right)$ & 1 & 3 & 2 & 4 & 3 \\
\hline Pour point $\left({ }^{\circ} \mathrm{C}\right)$ & -8.5 & -13 & -15 & -14 & -13 \\
\hline Flash point $\left({ }^{\circ} \mathrm{C}\right)$ & 72 & 79 & 83 & 87 & 95 \\
\hline Carbon residues $(\% \mathrm{w} / \mathrm{w})$ & 0.1 & 0.2 & 0.4 & 0.5 & 0.7 \\
\hline
\end{tabular}

\section{RESULTS AND DISCUSSIONS}

The experiments are performed at constant speed of 1500 rpm whereas at different loading conditions on the engine, i.e., $0 \%, 25 \%, 50 \%, 75 \%, 80 \%, 85 \%, 90 \%$ and $100 \%$. To check the repeatability of the results, the same sample is tested for three times and their average values are considered for analysing the results after duly eliminating the perturbed data.

The effect of the percentage of water in W/D emulsion on brake thermal efficiency (BTE) at various engine loads is shown in Fig. 3. It has been observed that there is a significant increase in thermal efficiencies of emulsion and diesel fuel with increase in load. This is due to reduction in heat loss and increase in power with increasing load. It has also been observed from Fig. 3 that there is a slight decrease in BTE up to $15 \% \mathrm{~W} / \mathrm{D}$ emulsion and then increases when $20 \%$ water in the emulsion is used. Lower BTE is due to lower heating value of fuel leading to decrease fuel energy to mechanical power conversion, although the microexplosion of water droplets can help to break down the oil droplets. But as the water percentage is increased to $20 \%$, the micro-explosion phenomenon may play a dominant role over the lowering of heating value of the emulsified fuel. As a result, more complete vaporization and turbulent mixing of the fuel and air take place, thereby improving the combustion process and the efficiency of the engine. The average increase in BTE for $20 \%$ W/D emulsion is approximately $2.5 \%$ compared with diesel fuel over the entire loading range for this diesel engine. Thus it can be inferred that there is no significant effect on BTE up to $15 \%$ W/D emulsion.

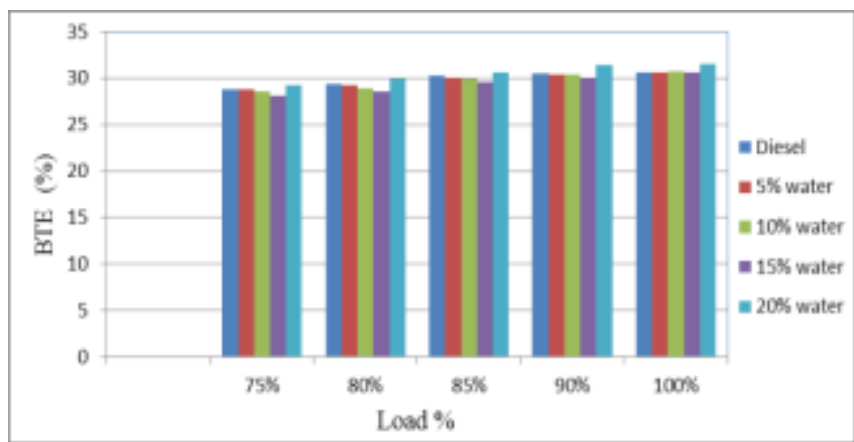

Fig -3: Comparative plot of BTE versus engine load 
Brake specific fuel consumption (BSFC) decreases with increase in engine load. This is due to the fact that the heat loss to the combustion chamber wall is proportionately greater and combustion efficiency is poorer at lower load resulting in higher fuel consumption for the same power production. The BSFC of emulsion diesel is higher than pure diesel. This may be due to its lower calorific value and the drop in brake power with water addition that increases fuel consumption for same desired output. BSFC increases with increase in water percentage which is shown in Fig. 4. This is because, as the percentage of water in the emulsion increases, a large amount of diesel is displaced by an equal amount of water and less amount of diesel fuel is actually contained within the emulsion [6]. The BSFC over the entire loading condition for $20 \%$ water emulsified diesel blend is approximately $25.85 \%$ higher than pure diesel in average.

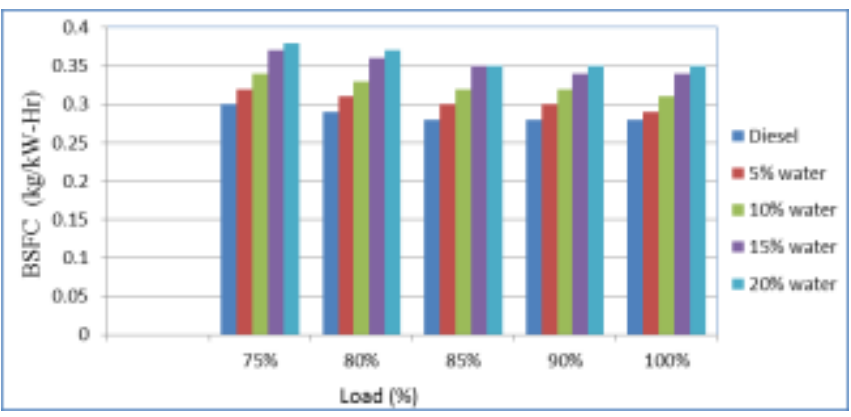

Fig -4: Comparative plot of BSFC versus engine load

The effect of brake specific energy consumption (BSEC) with increasing water percentage is shown in Fig. 5. The BSEC measures the amount of input energy required to develop one kilowatt power. It is a reliable parameter because it takes into account both mass flow rate and calorific value of the fuel. Although it is observed that the $20 \%$ water-diesel blend has the highest BSFC, but the BSEC of this blend is the lowest. Critical observation of Fig. 5 reveals that the BSEC increases up to $15 \%$ W/D emulsion and then decreases when $20 \%$ water in the emulsion is used. The contradicting effect of micro-explosion phenomena and decrease in heating value is clearly visible from this figure. Up to $15 \%$ water content, the micro-explosion phenomena may be suppressed by the decrease in heating value of the emulsified fuel. However, at $20 \%$ water content the trend reverses, which may be due to the dominant role played by micro-explosion phenomena causing better mixing of fuel and air. The average decrease in BSEC is $1.8 \%$ lower than pure diesel for $20 \%$ water emulsified diesel over the entire loading range.

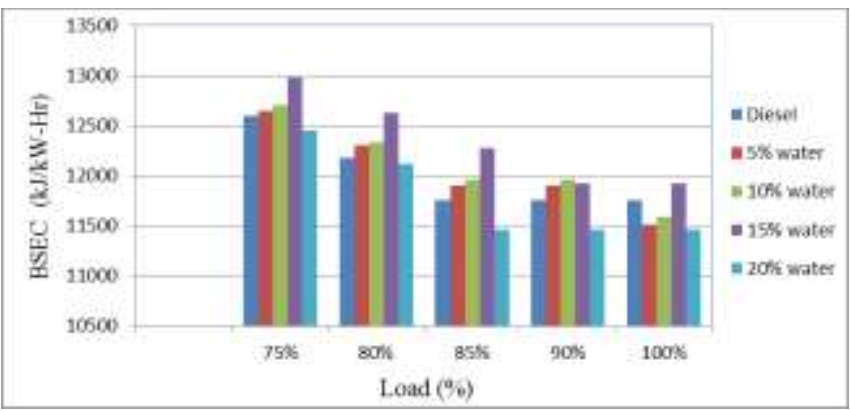

Fig -5: Comparative plot of BSEC versus engine load
As the percentage of water in the emulsion increases, the exhaust gas temperature (EGT) decreases which is shown in Fig. 6. This is due to the fact that the heat of combustion is absorbed by the additional water present within the diesel. The latent heat of water will cool the charge due to evaporation of water, and the cylinder average temperature becomes lower as the water percentage increases $[6,7]$. The $20 \%$ emulsified blend has the lowest EGT and is lower than diesel fuel by $8.6 \%$ in average over the entire loading condition.

$\mathrm{NO}_{\mathrm{X}}$ increases with engine load because increasing engine load increases the combustion chamber temperature. However, significant reduction of $\mathrm{NO}_{\mathrm{X}}$ has been observed with increasing percentage of water in the emulsion and is shown in Fig. 7. This happens because when water along with diesel enters the combustion chamber, it is directly vaporised into steam due to presence of high temperature and pressure inside the combustion chamber. This takes some of the heat from the combustion chamber and brings down the cylinder temperature, thus restraining the generation of $\mathrm{NO}_{\mathrm{X}}$. The $20 \%$ water-in-diesel blend gives a reduction in $\mathrm{NO}_{\mathrm{X}}$ emission up to $30 \%$ in average over the entire loading range.

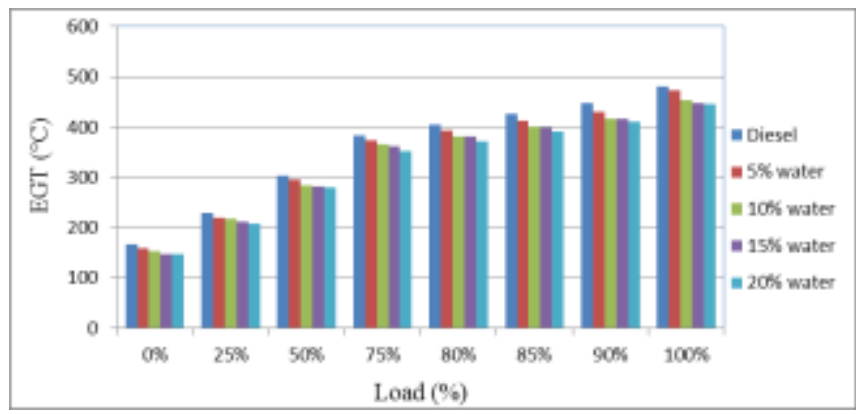

Fig -6: Comparative plot of EGT versus engine load

The variation of $\mathrm{CO}$ and $\mathrm{UBHC}$ emissions against engine load is shown in the Fig. 8 and Fig. 9. It is observed that both the emissions show similar trends; it decreased up to intermediate loads (up to 50\%) and then increased. The CO and UBHC emissions of the emulsified fuels are always higher than the pure diesel; it increases up to $15 \% \mathrm{~W} / \mathrm{D}$ emulsion and then decreases when $20 \%$ water in the emulsion is used. The increase in emissions is due to the fact that the emulsion fuel contains water which brings down the cylinder temperature slowing down the combustion of carbon, as a result of which incomplete combustion occurs. However, as explained in earlier, due to the dominant effect of micro-explosion phenomena with $20 \%$ W/D emulsified fuel blend, better mixing of reactants may be possible. As a result, $\mathrm{CO}$ emission is observed to have lower value with $20 \% \mathrm{~W} / \mathrm{D}$ emulsified fuel blend, although it is still higher than corresponding value with diesel fuel. 


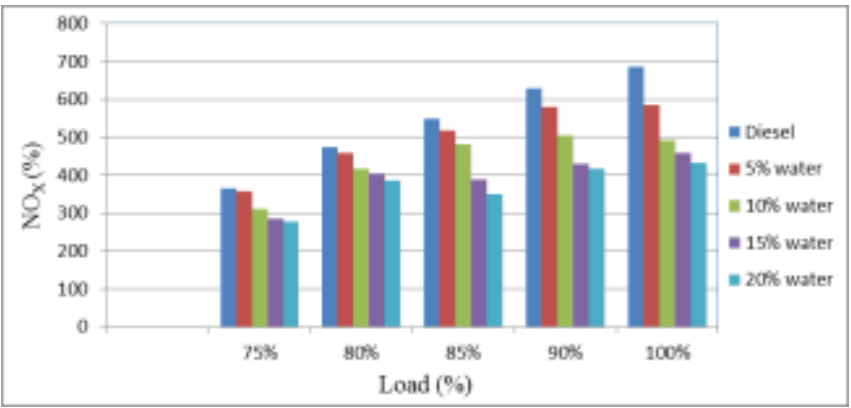

Fig -7: Comparative plot of $\mathrm{NO}_{\mathrm{X}}$ versus engine load

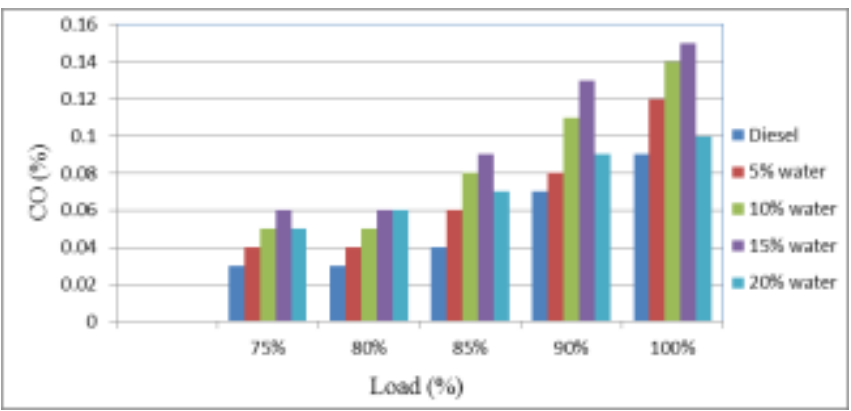

Fig -8: Comparative plot of CO emission versus engine load

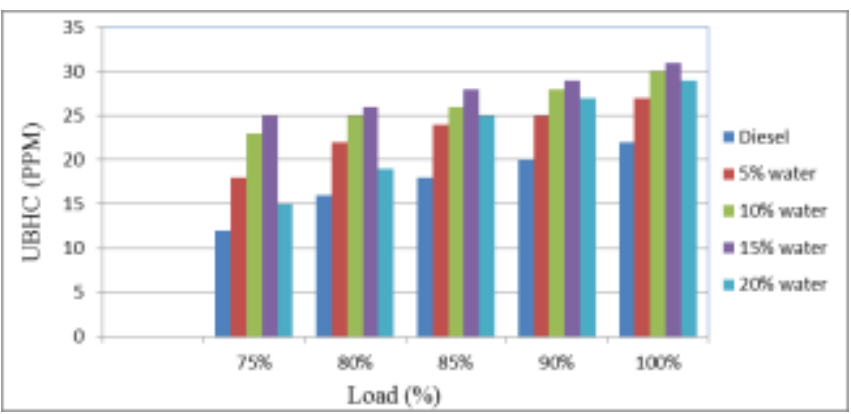

Fig -9: Comparative plot of UBHC emission versus engine load

Thus, from the above discussions it is evident that although the $\mathrm{CO}$ and UBHC emissions of W/D emulsified fuel are slightly higher than pure diesel, there is an enormous reduction in $\mathrm{NO}_{\mathrm{X}}$ emission using W/D emulsified fuel which is the major pollutant of diesel engines. The BTE with $20 \%$ W/D emulsified fuel is found to be higher than diesel. Hence, it can be concluded that among all the emulsified fuel blends that are considered in this work, the $20 \% \mathrm{~W} / \mathrm{D}$ emulsion emerged out to be the most suitable one having better BTE and lower $\mathrm{NO}_{\mathrm{X}}, \mathrm{CO}$ and UBHC emissions.

\section{CONCLUSION}

In the present work, the engine performance parameters and emission characteristics of a 4-stroke, water-cooled Diesel engine have been evaluated using water emulsified diesel oil as fuel in order to establish a suitable water/diesel ratio in the fuel. For that emulsified diesel fuel containing 5\%, 10\%, $15 \%$ and $20 \%$ water content are prepared using two surfactants namely Span80 and Tween80. The engine performance tests along with the corresponding emission measurements against engine loading $(0-100 \%)$ have been done on the experimental set-up for the various blends of emulsion diesel.
Based on the results obtained and its logical interpretation presented in the previous section, it is concluded that among all the emulsion blends considered in this work, 20\% W/D emulsion is the most suitable one considering various engine performance parameters, emission characteristics and local environmental conditions. This significant conclusion is arrived at, based on the following critical observations of the interpreted experimental results.

$>$ BSEC increases and BTE decreases up to $15 \% \mathrm{~W} / \mathrm{D}$ emulsion and when $20 \%$ water in the emulsion is used, BSEC decreases and BTE increases. The average increase in BTE for $20 \%$ W/D emulsion is approximately $2.5 \%$ higher than pure diesel over the entire loading condition.

$>$ BSFC increases with the increase in water percentage when emulsion is considered as total fuel. Whereas, the BSFC when the total fuel is considered strictly the amount of diesel fuel that is burned is minimum when $20 \% \mathrm{~W} / \mathrm{D}$ emulsion is used.

$>$ The EGT decreases as the percentage of water in the emulsion increases and is lower than diesel fuel by $8.6 \%$ in average when $20 \%$ blend is used over the entire engine load.

$>$ The presence of water in the W/D emulsion has, however, an undesirable effect on the performance of the engine by slightly reducing its peak torque and power due to decrease in heating value of the fuel blends.

$>$ The slight reduction in power can be compensated by the significant reduction in $\mathrm{NO}_{\mathrm{X}}$ emission when W/D emulsion is used. With the increasing percentage of water up to $20 \%$ in the emulsion, the $\mathrm{NO}_{\mathrm{X}}$ emission decreases up to $30 \%$ in average when the entire engine loads are considered.

$>$ The CO and UBHC emissions increase up to $15 \% \mathrm{~W} / \mathrm{D}$ emulsion and then decreases when $20 \%$ water in the emulsion is used; but these emissions are always higher than pure diesel.

Hence, water-in-diesel emulsion represents the simplest substitute to diesel fuel as the substitute element, i.e., water, is available at free of cost. Further, as found in this present work, this fuel mix does not require any engine modifications. Thus, if it passes the engine durability tests, it will be a great boon for the heavy duty trucks and buses.

\section{ACKNOWLEDGEMENT}

I do hereby acknowledge Prof. R. D. Misra, Department of Mechanical Engineering, NIT Silchar for giving me the opportunity to work in the IC engine lab of Mechanical Engineering Department, NIT Silchar and also for his moral support and guidance throughout the whole experimental work.

\section{REFERENCES}

[1]. Subramanian, K. A.; A comparison of water-diesel emulsion and timed injection of water into the intake manifold of diesel engine for simultaneous control of $\mathrm{NO}$ 
and smoke emissions, Energy Conversion and Management, 52, pp. $849-857,2011$.

[2]. Armas, O. et al.; Characterization of light duty diesel engine pollutant emissions using water-emulsified fuel, Fuel, 84, pp. 1011-1018, 2005.

[3]. Dryer, F.L.; Water addition to practical combustion systems - concepts and applications, 16th Symposium International on Combustion, The Combustion Institute, pp. 279-295, 1976.

[4]. Kadota, T. And Yamasaki, H.; Recent advances in the combustion of water fuel emulsion, Progress in Energy and Combustion Science, 28, pp. 385-404, 2002.

[5]. Lif, Anna and Holmberg, Krister; Water-in-diesel emulsions and related systems, Advances in Colloid and Interface Science, Issues 123-126, pp. 231-239, 2006.

[6]. Badran, Omar et al.; Impact of emulsified water/diesel mixture on engine performance and environment, International Journal of Thermal and Environmental Engineering, Vol. 3, Issue 1, pp. 1-7, 2011.

[7]. Abu-Zaid, M.; Performance of single cylinder, direct injection diesel engine using water fuel emulsions, Energy Conversion and Management, 45, pp. 697-705, 2004.

[8]. Samec, Niko et al.; Numerical and experimental study of water/oil emulsified fuel combustion in a diesel engine, Fuel, 81, pp. 2035-2044, 2002.

[9]. Dibofori-Orji, A.N.; Critical processes involved in formulation of water-in-oil fuel emulsions, combustion efficiency of the emulsified fuels and their possible environmental impacts, Research Journal of Applied Sciences, Engineering and Technology, Vol. 3, Issue 8, pp. 701-706, 2011.

\section{BIOGRAPHIE}

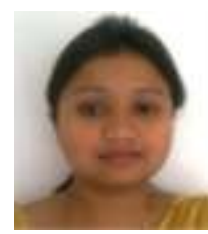

Sangeeta Das is a research scholar in the Department of Mechanical Engineering, NERIST. She has completed her M. Tech from NIT Silchar in the year 2013 and B.Tech from Tezpur University in the year 2010. She has also worked as an Assistant Professor in the Department of Mechanical Engineering, GIMT, Guwahati for a period of 3 years. 